\begin{tabular}{|c|c|} 
UÁQUIRI & PPG \\
\hline & Revista do Programa de Pós-Graduação em Geografia \\
UÁQUIRI - PPGGEO, v.2, n. 2, p. 7 - 26, ano 2020 & \\
\hline
\end{tabular}

\title{
OS EFEITOS DA REFORMA TRABALHISTA IMPLEMENTADA NO GOVERNO TEMER SOBRE O ESTADO DO ACRE
}

\author{
Ângela Maria Bastos de Albuquerque ${ }^{1 *}$, Juliana Santos de Souza Cunha ${ }^{1}$. \\ ORCID: https://orcid.org/0000--0002-2472-7664; https://orcid.org/0000-0002-6980-3114
}

${ }^{1}$ Mestrandas do Programa de Pós-Graduação em Geografia da Universidade Federal do Acre, Rio Branco, Acre,
Brasil.
*angela.mbb@gmail.com

Recebido em: 22/09/2020 Aceito em: 19/11/2020 Publicado em: 20/12/2020 DOI: https://doi.org/10.47418/uaquiri.vol2.n2.2020.4378

\begin{abstract}
RESUMO
$\mathrm{O}$ artigo analisa os efeitos da Reforma Trabalhista implementada no governo do Presidente Michel Temer sobre o estado do Acre a partir de referenciais teóricos como o sociólogo Ricardo Antunes, do geógrafo Antonio Thomaz Junior (2018) e com o apoio de um levantamento bibliográfico de pesquisas relacionadas à Reforma Trabalhista após o ano de 2017. O objetivo foi identificar, registrar e analisar como as pessoas, as instituições econômicas, sociais, civis e políticas no Acre perceberam o processo da Reforma Trabalhista e seus efeitos sobre a sociedade brasileira e acreana. A partir dos posicionamentos midiáticos, principalmente dos jornais locais acreanos identificamos como a Reforma Trabalhista tem impactado no desemprego, no número de desocupados, nas formas de trabalhos autônomos, no enfraquecimento do Ministério do Trabalho e no endividamento da sociedade acreana. Constatamos que por ocasião da Reforma Trabalhista, apesar de ser efetivada por um presidente com apenas $5 \%$ de aprovação social e envolto em inúmeras formas de corrupção, a sociedade acreana, e a sociedade brasileira de maneira geral, estavam numa espécie de letargia lúcida, sem demonstração de reações, sobre as mudanças nefastas que estavam para afetar diretamente os mais novos ingressantes no mercado de trabalho e as gerações futuras.
\end{abstract}

Palavras-chave: Reforma Trabalhista; Acre; Precarização.

\section{THE EFFECTS OF THE LABOR REFORM IMPLEMENTED IN THE GOVERNMENT TEMER ON THE STATE OF ACRE \\ ABSTRACT}

The article analyzes the effects of the Labor Reform implemented in the Michel Temer government on the State of Acre from theoretical references such as sociologist Ricardo Antunes, from geographer Antonio Thomaz Junior (2018) with the support of a bibliographic survey of research related to Labor Reform after the year 2017. The objective was to identify the record and analyze how people, and economic, social, civil, and political institutions in Acre, perceived the Labor Reform process and its effects on Brazilian and Acre society. From the media positions, mainly from local newspapers, Acre people identified how the Labor Reform has impacted unemployment, the number of unemployed people, the forms of autonomous work, the weakening of the Ministry of Labor and the indebtedness of the Acre society. We found that at the time of the Labor Reform, despite being implemented by a president with only $5 \%$ of social approval and involved in numerous forms of corruption, Acre society, 
and Brazilian society in general, were in a kind of lucid lethargy, without no reactions, no indignation about the harmful changes that were about to directly affect the newest entrants to the job market and future generations.

Keywords: Labor Reform; Acre; Precariousness.

\section{LOS EFECTOS DE LA REFORMA LABORAL IMPLEMENTADA EN EL TEMPOR DE GOBIERNO EN EL ESTADO DE ACRE RESUMEN}

El artículo analiza los efectos de la Reforma Laboral implementada en el gobierno de Michel Temer en el Estado de Acre a partir de referencias teóricas como el sociólogo Ricardo Antúnez, del geógrafo Antonio Thomaz Junior (2018) con el apoyo de una encuesta bibliográfica de investigación relacionada con la Reforma Laboral después el año 2017. El objetivo era identificar registrar y analizar cómo las personas y las instituciones económicas, sociales, civiles y políticas en Acre percibían el proceso de Reforma Laboral y sus efectos en la sociedad brasileña y en Acre. Desde las posiciones de los medios, principalmente de los periódicos locales, la gente de Acre identificó cómo la Reforma Laboral ha impactado el desempleo, el número de personas desempleadas, las formas de trabajo autónomo, el debilitamiento del Ministerio de Trabajo y el endeudamiento de la sociedad de Acre. Descubrimos que en el momento de la Reforma Laboral, a pesar de ser implementado por un presidente con solo el 5\% de aprobación social e involucrado en numerosas formas de corrupción, la sociedad Acre y la sociedad brasileña en general, estaban en una especie de letargo lúcido, sin reacciones, sin indignación por los cambios dañinos que estaban a punto de afectar directamente a los nuevos participantes en el mercado laboral y las generaciones futuras.

Palabras clave: Reforma laboral; Acre; Precariedad.

\section{INTRODUÇÃ̃O}

A motivação para escrita deste artigo emergiu das discussões em sala de aula durante o cumprimento da disciplina Geografia do Trabalho e Conflitos Territoriais na Amazônia sob a responsabilidade do professor Dr. José Alves, no curso de Mestrado em Geografia do Programa de Pós-Graduação em Geografia - PPGEO, da Universidade Federal do Acre - UFAC, no segundo semestre de 2019. Buscou-se uma delimitação de análise da Reforma Trabalhista no governo Temer a partir da realidade socioeconomica do estado do Acre. A bibliografia indica que enquanto houve verdadeira apatia e indisposição social de resistência sobre a reforma, empresários e dirigentes institucionais de associações industriais e comerciais, acompanharam atentamente as novas mudanças nas relações trabalhista, em tom de conquistas para a classe patronal acreana. As análises levam em conta a realidade da economia acreana baseada na dependência do funcionalismo público, da produção extrativista vegetal, com predominância do setor terciário e de serviços.

Concomitante à aprovação da Reforma Trabalhista, variadas instituições e analistas emitiram opiniões e pareceres sobre as alterações apresentadas. Na opinião do pesquisador da Fundação Instituto de Pesquisas Econômicas - FIPE, Chahad (2017), a reforma promovida pelo 
governo Michel Temer foi a mais profunda Reforma Trabalhista desde a promulgação da própria Consolidação das Leis do Trabalho - CLT, em 1943, tendo em vista que as reformas anteriores foram pontuais, e esta, perpassou todo o conjunto das legislações que estavam em vigor até 2017. No ano seguinte à reforma, Costa e Almeida (2018), analisaram as mudanças propostas pela Reforma Trabalhista e os seus principais impactos para os trabalhadores. As autoras compreenderam que houve uma dissimulação sob um discurso de garantir maior autonomia para o trabalhador e para o empregador, mas, que, na verdade, a reforma trouxe maior exploração do trabalhador e desproteção por parte das legislações.

Para além das contribuições dessas pesquisas, o presente trabalho contou adicionalmente com a obra de Antunes (2002), além de duas entrevistas desse sociológo. A primeira para Sanz; Nader reporteres do Jornal Correio da Cidadania, e a segunda para a Agência de Notícias Brasil de Fato. Também foram utilizadas as obras de Teixeira et al (2017), Ramos et al (2017) e Krein et al (2018). A primeira obra constui-se em um dossiê da Reforma Trabalhista dividido em dois blocos: os contra-argumentos à desconstrução dos direitos, e os impactos da reforma sobre a realidade dos trabalhadores brasileiros. No segundo, Ramos et al (2017) apresenta variadas narrativas de ressistências em face das estratégias para construção da reforma trbalhista, construida a partir do golpe de usurpação do cargo da presidenta Dilma Vana Rousseff completa em 2016. Na obra de Krein et al (2018), em seus nove capítulos analisa desde os impactos da Reforma Trabalhista sobre a classe assalariada, até o financiamento da previdência social com ênfase na pejotização e formalização.

Esse acervo bibliográfico contribui para ampliar a compreensão dos efeitos da Reforma Trabalhista implementada no Governo Temer sobre o estado do Acre, que foi o objetivo central do presente trabalho. Perseguindo esse objetivo, a primeira seção traz uma análise da reforma sob uma perspectiva teórico crítica, de Thomaz Junior (2018), além dos pesquisadores Mészáros (1995) e Teixeira (2017), entre outros pesquisadores e pesquisadoras que adentram no campo analítico do mercado de trabalho. Após um breve registro metodológico, a segunda seção buscou identificar os comportamentos da sociedade política, civil, industrial e comercial acreana diante da Reforma Trabalhista em tela seguido de uma análise discussiva sobre os efeitos da reforma no estado do Acre. Após esse último objetivo, foi realizada uma breve retomada nas considerações finais, pela identificação dos eixos centrais do trabalho, seguido de um posicionamento analítico do contexto socioeconomico e político dos governos Temer e Bolsonaro. 


\section{METODOLOGIA}

A escrita do artigo foi orientada pela pesquisa bibliográfica com abordagem qualitativa, pela utilização de artigos de jornais, documentos estatísticos e legislações do campo trabalhista. O levantamento bibliográfico foi consubstanciado pelas pesquisas com abordagens numa concepção histórico críticas sobre a Lei n 13.467 , de 13 de julho de 2017, referente à Reforma Trabalhista aprovada no governo Temer, e suas consequências sobre o trabalhador brasileiro. Para atender a proposta temática, os artigos dos jornais foram escolhidos a partir da mídia online acreana com foco na Reforma Trabalhista acima mencionada, destacando: parlamentares acreanos favoráveis e contrários à reforma, instituições, associações e grupos empresariais favoráveis e movimentos sindicais contrários às propostas aprovadas na atual legislação que implementou a Reforma Trabalhista no Brasil.

A pesquisa com recortes jornalísticos tem sido analisada por Lapuente (2015), ao apresentar as vantagens de focar diretamente e de forma objetiva a temática pesquisada, por poder contribuir nas discussões do contexto das análises propostas na pesquisa e por se constituir material que forma o conjunto de fontes históricas que ficam disponíveis ao pesquisador para ser reutilizada a qualquer tempo, ou lugar, em nível de comparação, para agregar informações ou subsidiar discussões de caráter analítico discursivas. Os cuidados com a utilização desse tipo de material são descritos por Lapuente, (2015), ao lembrar que as fontes jornalísticas precisam ser filtradas, por atender aos interesses de quem escreve e por estar propensa a expor parcialmente informações relevantes que podem omitir intencionalmente conteúdos de interesses do patrocinador da notícia.

A partir dessa assertiva, os comentários no presente trabalho, foram confrontados com as opiniões emitidas em uma entrevista jornalística realizada por Sanz; Nader, (2016), ao captar as opiniões do sociólogo Ricardo Antunes sobre as temáticas discutidas durante a pesquisa. Houve adicionalmente o cuidado de inserir as constatações de teóricos da área da geografia do trabalho, nos contextos das discussões, para assegurar a coerência analítica dos objetivos propostos. As contribuições teóricas de Thomaz Junior, Mészáros e Teixeira, pavimentaram o caminho para uma discussão centrada nas questões trabalhistas, a partir dos efeitos da reforma de 2017 sobre a sociedade acreana em suas mais diversas representações: empresariais, trabalhistas, midiáticas e políticas. 


\section{FUNDAMENTAÇÃO TEÓRICA}

\subsection{A Reforma Trabalhista no governo Temer sob uma perspectiva teórico crítica}

Na concepção de Thomaz Junior (2018, p. 8), "a vigência do processo de reestruturação produtiva do capital" impõe as mudanças nefastas que estão ocorrendo, no âmbito do trabalho, afinadas aos reordenamentos daí decorrentes, os quais, desde o final dos anos de 1980, orientam novas linhas de expressão do conflito social, isto é, "não se restringindo apenas ao formato clássico capital versus trabalho, mas envolvendo outras formas de configuração da dominação de classe, de sorte a implicar novos olhares sobre as delimitações clássicas". Essas mudanças foram profundamente revisadas, para pior, com a Reforma Trabalhista, já em vigor, após dezembro de 2017, no Brasil, tanto para trabalhar no campo (assalariado, camponês) e para "trabalhar na cidade (assalariados, por conta própria, intermitentes, informais), sob distintas relações sociais de produção e de trabalho". (THOMAZ JUNIOR 2018, p. 8).

A Reforma Trabalhista implementada pela Lei $n^{\circ} 13.467$, de 13 de julho de 2017 no governo de Michel Temer, foi parte de um conjunto de outras reformas intencionadas pela classe empresarial empregatícia, sob o espectro de um vice-presidente empossado pela usurpação do cargo, com apoio midiático, da classe política legislativa e judiciária. A ementa da Lei n ${ }^{\circ}$ 13.467, informa que houve alteração na "Consolidação das Leis do Trabalho (CLT), aprovada pelo Decreto-Lei $n^{0} 5.452$, de $1^{\circ}$ de maio de 1943 , e as leis $n^{\circ} 6.019$, de 3 de janeiro de 1974, a Lei $\mathrm{n}^{\circ} 8.036$, de $1^{\circ}$ de maio de 1990, e 8.212, de 24 de julho de 1991". (BRASIL, 2017). Na sombra de discursos forjados por supostas infrações e corrupções, a Reforma Trabalhista foi construída e efetivada sob olhares imobilizantes de uma sociedade ávida por mudanças políticas, econômicas e sociais, a qualquer preço, a ser pago pelos ingressantes no atual mercado de trabalho, e pelas futuras gerações de trabalhadoras e trabalhadores brasileiros.

Esse contexto coaduna com as assertivas de Alves (2014, p. 71) ao afirmar que "o Brasil, nas últimas décadas, ao se inserir na lógica da reestruturação produtiva do capital internacional, o fez de modo a reforçar as desigualdades sociais e territoriais, pois o Estado passou a atuar com uma política direcionada ainda mais para o capital rentista". Mesmo antes dos efeitos das reformas trabalhistas e previdenciárias, Alves (2014, p. 106), já registrava que havia um movimento para redução dos direitos trabalhistas pela força de trabalho, e "um ataque aos direitos trabalhistas obtidos em período anterior, [com] terceirização nos espaços produtivos, a polivalência da mão de obra, redução de salário". 
Pela essência dos princípios em uma sociedade capitalista em que a disputa econômica não se restringe apenas aos donos do capital, é possível compreender a imobilidade assumida pela classe trabalhadora brasileira por ocasião da reforma. Pelas assertivas de Mészáros (1995, p. 132), "em nossa sociedade, os incentivos materiais tal como nos são apresentados sempre colocam as pessoas umas contra as outras". Essa afirmação situa-se tanto entre as pessoas, individualmente, quanto aos gestores institucionais, pois o referido autor enfatiza que os incentivos operam na presunção de que é possível dividir as pessoas para melhor controlá-las. Essa realidade ficou mais visível pela Reforma Trabalhista que foi construída e aprovada na gestão de um presidente com apenas $5 \%$ de aprovação popular.

Em suas análises sobre o conjunto de ações arquitetadas para atender as demandas do capital sobre o trabalho, Teixeira et al (2017, p. 28) compreende que a estratégia de desmonte das políticas sociais e de retirada de direitos serve a dois propósitos: "reduzir o tamanho do Estado na formulação e implementação de políticas públicas, reservando fatias cada vez maiores para a iniciativa privada em setores como saúde e educação, e possibilitar a privatização de empresas públicas" a exemplo da Petrobras, entre outras. Ainda outra intencionalidade da Reforma Trabalhista, segundo a mesma autora, foi dificultar a comprovação de tempo de contribuição dos trabalhadores sob pretexto das flexibilizações de contratações de trabalhos intermitentes, parciais, autônomos e temporários.

Essa percepção pode ser entendida sob as assertivas de Thomaz Junior (2018), ao afirmar que as formas sutis que põem os trabalhadores em condições desfavoráveis podem ser melhor compreendidas na vivência do dia a dia, compreendendo como acontece as relações de vida e sobrevivência nos campos, nas comunidades desfavorecidas, entre as famílias que utilizam variadas estratégias para continuar lutando e sobrevivendo sobre a exploração trabalhista. Ao tratar do movimento do tecido do trabalho e a reestruturação do capital, Thomaz Junior (2018), mostra que é no interior desse movimento que transcorre variados embates e é através do tecido do trabalho que se pode efetivamente compreender as lutas de cunho emancipatório e as diversas expressões do desemprego.

A constante luta a ser travada contra a lógica do capital, se justifica pelas insistentes tentativas de fragilização da classe trabalhadora em beneficio do que Silva e Leite (2017), identificam como os incrementadores do poder de ganho de referidos setores, que são os (grandes conglomerados empresariais e industriais, do agronegócio, dentre outros), "em detrimento, como sempre, dos direitos basilares da classe trabalhadora, aumentando, desta 
forma, o abismo social existente entre a classe que vive do lucro e aquela que vive da venda da força de trabalho". (SILVA E LEITE 2017, p. 41).

Tanto a Reforma Trabalhista no governo do Presidente Michel Temer quanto à reforma previdenciária do governo Presidente Jair Messias Bolsonaro em 2019, aconteceram em um contexto de produção discursiva apoiada não apenas nos pressupostos da corrupção e das infrações nas gestões, como também na alegação de que as legislações trabalhistas eram antigas e mantidas por legislações constitucionais ultrapassadas, que não atendiam às demandas das novas empresas conectadas virtualmente em sistemas de informações tecnologicamente avançados, que demandavam novas legislações e atualizações trabalhistas.

Essa realidade é identificada por Thomaz Junior (2018, p. 30-31), que compreende haver pelo menos dois fenômenos contrários e simultâneos, ocorrendo sobre o trabalho: "De um lado, a fragmentação e a dispersão espacial e temporal e, de outro, sob os efeitos das tecnologias da informação, a compressão do espaço, ou seja, tudo se passa aqui, sem distâncias, diferenças, nem fronteiras, e a compressão do tempo". Para esse autor, esses são os novos fatores que diferenciam a atual sociedade das anteriores.

Foi nesse contexto, de alarmantes e inflamados discursos, falsas expectativas, exposições éticas e morais de adversários políticos com apoio midiático, que a atual Reforma Trabalhista e previdenciária foram aprovadas e implementadas. Para uma visão panorâmica dos efeitos nefastos da Reforma Trabalhista, Teixeira et al (2017), elencam pelo menos seis pontos crivos que indicam irreparáveis prejuizos à classe trabalhadora. São eles:

1. Formas de contratação mais precárias e atípicas: terceirização, contrato intermitente, parcial, autônomo, temporário, negociação da dispensa. 2 . Flexibilização da jornada de trabalho: jornada in itinere, ampliação da compensação do banco de horas, redução do tempo computado como horas extras, extensão da jornada 12 por 36 para todos os setores de atividade, flexibilidade diária da jornada, redução do intervalo de almoço, parcelamento de férias, negociação individual do intervalo para amamentação. 3. Rebaixamento da remuneração: pagamento por produtividade, gorjetas, pagamento em espécie, PLR (Participação nos Lucros ou Resultados), abonos e gratificações, livre negociação dos salários. 4. Alteração das normas de saúde e segurança do trabalho: insalubridade (gestante e lactante), restrições à fiscalização, teletrabalho. 5. Fragilização sindical e mudanças na negociação coletiva: fragmentação da classe, descentralização das negociações, regras para a representação no local de trabalho, formas de custeio da organização sindical. 6. Limitação do acesso à Justiça do Trabalho e limitação do poder da Justiça do Trabalho: ampliação do papel dos mecanismos privados de conciliação, eficácia liberatória dos acordos, quebra do princípio da gratuidade. (TEIXEIRA et al 2017, p. 61). 
A partir do exposto, a intenção foi compreender a Reforma Trabalhista do governo Michel Temer sob uma perspectiva teórico crítica, desnudada de falácias e argumentos discursivos que encobrem os reais efeitos das recentes reformas sobre a classe trabalhadora brasileira. Fato é que além de variadas ações arquitetadas desde o impeachment da presidenta Dilma Rousseff, em 31 de agosto de 2016, foi necessário o apoio de uma parcela da sociedade e de grupos empresariais, políticos e econômicos para se alcançar a implementação da Reforma Trabalhista.

\subsection{Comportamentos da sociedade política, civil, industrial e comercial acreana diante da Reforma Trabalhista implementada no Governo Temer.}

Registramos nesta seção algumas informações e apontamentos sobre o posicionamento dos representantes políticos do Acre no processo de aprovação da Reforma Trabalhista implementada no governo de Michel Temer no ano de 2017. A começar pela votação da reforma no Senado Federal, que teve aprovação do ex-senador e atual governador do estado do Acre, Gladson Cameli (PP-AC) e do senador Sérgio Petecão (PSD-AC); o voto contrário à reforma foi do ex-senador Jorge Viana do Partido dos Trabalhadores.

Em uma entrevista, Ricardo Antunes acredita que "as reações da sociedade brasileira as cenas de casais brancos de classe média indo para a manifestação com a babá cuidando de seus filhos, somadas à idiotia dominante que berrava em frente à FIESP, são emblemáticas". Essas manifestações tomaram a FIESP como espaço arquitetônico que simbolizou seu grito, o que é uma expressão eivada de significado. (SANZ; NADER, 2016). No estado do Acre, aquelas manifestações se concentraram em frente ao Palácio Rio Branco com pessoas portando roupagens verdes amarelas, bandeira do Brasil e do Acre, com palavras de ordem contra o partido dos trabalhadores.

Essas reações foram reafirmadas no ano seguinte, por ocasião da eleição que elegeu o atual presidente Jair Bolsonaro, que deu continuidade às reformas, implementando outra reforma que interessava à classe patronal e à elite econômica brasileira, a reforma da previdência. Neste pleito, a sociedade acreana foi a segunda que mais votos elegeram o presidente da reforma previdenciária. A sequência dos acontecimentos indicou que havia um único movimento reformista, tanto trabalhista, quanto da previdência, com indicativos de um movimento planejado e coordenado para atender aos interesses dos políticos, empresários e o setor econômico comandado pelo capital. 
Conforme registrado por Sanz; Nader (2016), os votos dos dois parlamentares acreanos em favor da Reforma Trabalhista foram apoiados pelos representantes da Associação Comercial do Acre - Acisa, juntamente com vários outros "diretores da entidade, dentre eles o presidente da Adacre (Associação dos Distribuidores e Atacadistas do Acre), Júnior Sperotto e o presidente da AJE-AC (Associação de Jovens Empresários do Acre), Ramon Guedes, para formar opinião em relação ao voto sobre a Reforma Trabalhista". (SANZ; NADER, 2016, p. 4). Conforme noticiado no site da Acisa, "na ocasião, todos os diretores se mostraram favoráveis e declararam apoio aos parlamentares Alan Rick (PRB-AC), Flaviano Melo (PMDB-AC) e Jéssica Sales (PMDB-AC que votaram a favor da reforma", ACISA, 2017).

Nas palavras de Antunes (2002, p. 33), “em meio a tanta destruição de forças produtivas [...] eleva-se a intensidade dos níveis de desemprego estrutural". Esse fato ficou evidente pelas afirmações encontradas em Sanz; Nader (2016), sobre as instituições: "FIESP, FEBRABAN, associações comerciais, grande mídia; todos estão dizendo que o governo Dilma não os interessa e encerrou o ciclo da conciliação pelo alto. Agora é o momento do golpe. Mas o golpe não é militar como o de 1964". É um golpe urdido no pântano parlamentar. (SANZ; NADER, 2016, p. 5). Os discursos produzidos na mídia nacional foram reproduzidos na mídia local acreana. A força que o Partido dos Trabalhadores havia demonstrado por longos 20 anos no Acre estava em vias de evaporação. Na entrevista de Ricardo Antunes, o sociólogo acredita que “o PT acreditou 'na tese da Margareth Thatcher, do 'capitalismo popular' na ideologia e na aliança capital e trabalho em prol do crescimento do país". (SANZ; NADER, 2016, p. 5). O referido autor afirma que "ele acreditou em uma coisa muito velha e abandonou o que tinha de mais positivo quando era jovem", a sua ousadia e sua pujança de classe. (SANZ; NADER, 2016, p. 5). Naquela ocasião, também no Acre, os partidos de esquerda respiravam por aparelho, por assim dizer.

Mesmo diante de um Congresso ética e moralmente desmoralizado e com o líder da Reforma Trabalhista, Michel Temer, apresentando aprovação social de 5\%, os diretores da Associação Comercial do Acre entenderam que a reforma estava sendo feita com amplo debate junto à sociedade, e que as mudanças iriam trazer segurança jurídica a temas que vinham "sendo trabalhados na relação entre empresa e trabalhador". Para esses diretores, os "direitos trabalhistas como férias, $13^{\circ}$ salário, FGTS", não seriam alterados, em sua opinião, bastava "uma leitura simples no projeto para verificar que a população vem sendo induzida ao erro" (ACISA, 2017). 
Na mesma notícia, indicava-se que o deputado Alan Rick, que fazia parte da "Frente Parlamentar Mista em Defesa do Comércio, Serviço e Empreendedorismo, respondeu a vários questionamentos". A matéria afirmava ainda que "o parlamentar se pronunciou através de vídeo nos canais de comunicação e nas redes sociais, pontuando as razões que justificam seu voto". O deputado enfatizou que estava "havendo uma má interpretação por parte dos trabalhadores e que a reforma é essencial para o Brasil voltar a crescer e gerar empregos". (ACISA, 2017).

Após a reforma aprovada, o regime de férias do trabalhador foi alterado, divergindo da opinião do vice-governador Wherles Fernandes da Rocha, ao constatar que antes, as férias poderiam ser divididas em até dois períodos sendo que um deles não poderia ser menor que dez dias. Com a reforma, as férias poderão "ser dividida em até três períodos, se houver concordância do empregado, sendo que um deles não pode ser menor que 14 dias" (ACISA, 2017). Entre os pontos omitidos nas produções discursivas dos defensores da Reforma Trabalhista, estavam o que Teixeira et al (2017, p. 61) destacou como "formas de contratação mais precárias e atípicas: terceirização, contrato intermitente, parcial, autônomo, temporário, negociação da dispensa". Não raro, a elite econômica não comentavam esses que eles consideravam pontos polêmicos, que flagrantemente fragilizam os direitos dos trabalhadores.

Em um movimento tímido, mas contrário às reformas, as jornalistas Brasil e Melo (2017, p. 3), registraram os protestos das centrais sindicais na cidade de Rio Branco. "Trabalhadores de várias categorias protestaram contra a Reforma Trabalhista e também contra a privatização dos Correios e Eletrobras". A manifestação foi realizada em frente à Prefeitura de Rio Branco, no Centro da capital, "com representantes dos sindicatos de professores, bancários, urbanitários, mototaxistas e motofretes". (BRASIL E MELO 2017 p. 3). Com os contra-movimentos apoiados pelas elites econômicas, realizados concomitantes aos das centrais sindicais, as manisfestações contrárias à Reforma Trabalhista exerciam mais caráter simbólico de manifestações, do que atender aos objetivos que era sensibilizar parlamentares acreanos a votarem contrários à Reforma Trabalhista.

Conforme noticiado por Brasil e Melo (2017), as manifestações aconteceram em todo o país, e no Acre, foram fortalecidas pela presença de representantes dos Correios, Bancários, urbanitários e professores. Duas daquelas categorias estavam ameaçadas pela privatização: trabalhadores da Eletroacre, Companhia de Eletricidade do Acre, que foi privatizada em 30 de agosto de 2018, e funcionários dos Correios que estão com as mesmas procupações com o governo Bolsonaro. Considerando o Acre o segundo Estado mais votante no atual governo, fica evidente que muitos manifestantes lutavam por seus direitos individuais, para não perderem o 
seu emprego ou direitos trabalhista. Sobre essa luta que é marca relevante dos sindicatos, na entrevista concedida a Sanz; Nader (2016), Ricardo Antunes salientou que os sindicatos estão mais próximos aos interesses imediatos da classe trabalhadora, "mas muitas vezes se perdem também nesses interesses imediatos ou são prisioneiros de um burocratismo e de uma política negocial e de conciliação. Isso pode fazer com que percam frequentemente o sentido de pertencimento de classe que deveriam ter". (SANZ; NADER, 2016, p. 7).

O resultado foi que após a aprovação da Reforma Trabalhista, Teixeira et al (2017, p. 61) constatou que a reforma "provocou flexibilização da jornada de trabalho com a jornada in itinere, ampliação da compensação do banco de horas, redução do tempo computado como horas extras, extensão da jornada 12 por 36 para todos os setores de atividade", flexibilidade diária da jornada, redução do intervalo de almoço, parcelamento de férias, negociação individual do intervalo para amamentação. Se antes já havia uma superexploração do trabalho, "favorecimentos patronais nas formas de degradação, de precarização, de terceirização, de intensificação da jornada de trabalho, após a reforma trabalhista, essas perniciosas condições foram elevadas ao extremo do possível". (TEIXEIRA et al 2017, p. 61).

\section{UMA VISÃO DA REFORMA TRABALHISTA SOBRE O ESTADO ACRE}

A população acreana foi estimada pelo IBGE em 881.935 habitantes no ano 2018, distribuída na proporção de 4,47 hab./ $\mathrm{km}^{2}$, no ano anterior, em 2017. O Instituto diz que mais de $90 \%$ da economia dos municípios acreanos dependem da administração pública, e a mesma fonte indica que o rendimento per capita, em 2018, foi de $\mathrm{R} \$ 909,00$, com 322 mil pessoas acima de 16 anos ocupadas. Desse total, os trabalhadores formais representavam 39,4 mil pessoas, com rendimento médio real habitual do trabalho principal das pessoas de 14 anos ou mais de idade, ocupadas na semana de referência em trabalhos formais no valor médio de R\$ $2.398,00$, entre as pessoas ocupadas na administração pública, defesa e seguridade social o quantitativo foi em média 36.527 pessoas.

Nas constatações de Alexandre et al (2017, p. 218-222), [...] no Brasil, a taxa de desocupação saltou de $12 \%$, quando correspondia a 12,3 milhões de pessoas, no último trimestre de 2016, para $13,7 \%$ no primeiro trimestre de 2017, atingindo 14,2 milhões de brasileiros".

Os pesquisadores indicam que no estado do Acre, no $4^{\circ}$ trimestre de 2016, o número de desocupados foi de 37.427 , enquanto no $1^{\circ}$ trimestre de 2017 , esse número foi ampliado para 51.644, perfazendo um total de 4.217 "novos desocupados" naquele período. Em comparação 
aos outros Estados brasileiros, o estado do Acre foi o que passou pelo maior crescimento proporcional da desocupação do país, 4,2 pp. entre 2016 e 2017.

No ano seguinte, em 2018, as instituições midiáticas acreanas, a exemplo do Jornal $O$ Alto Acre ${ }^{1}$ informaram com base nos resultados das pesquisas do IBGE, que o governo havia prometido criar 2 milhões de vagas de emprego em todo o país, por ocasião da Reforma Trabalhista, mas, havia conseguido apenas 298.300 oportunidades de emprego. Considerando que a mesma fonte apontava que no período daquela promessa, o país havia atingido 13,3 milhões de desempregados, com uma taxa de desocupação de $12,8 \%$, ainda que tivesse conseguido este feito de criar os 2 milhões de empregos, ainda assim, teria resolvido apenas $15 \%$ do problema, levando-se em conta os 13,3 milhões de desempregados naquela ocasião ${ }^{2}$.

Nas assertivas de Prieb; Carcanholo (2011), esse contingente de desempregados é parte do excedente de trabalhadores desocupados, produzidos pelas vias das contradições do sistema capitalista de produção e pela precarização e flexibilização do trabalho, que leva as empresas a buscar "novas formas de contratação de força de trabalho como empregos temporários, subcontratação, trabalho terceirizado, entre outros, em que os salários são mais baixos e os direitos dos trabalhadores, cada vez menores". (PRIEB; CARCANHOLO, 2011, p. 154).

Outra questão apontada pelo jornal $O$ Alto Acre foi o aumento da informalidade que atingiu 37,3 milhões de trabalhadores em 2017. O número representava um crescimento de 1,7 milhão com relação a 2016. A matéria enfatizou que "o total de trabalhadores informais em 2017 representa 40,8\% de toda a população ocupada (que exerce alguma atividade remunerada) no país, e que a Reforma Trabalhista representava uma promessa de diminuir a informalidade no Brasil"3.

Na concepção de Costa e Almeida (2018), o trabalho autônomo apresenta repercussão direta no acesso aos benefícios previdenciários, impondo sobre sua responsabilidade, o encargo de realizar o recolhimento previdenciário nos termos da lei 8.212/1991, a qual esclarece em seu art. 21 que "a alíquota de contribuição dos segurados contribuinte individual e facultativo será de vinte por cento $(20 \%)$ sobre o respectivo salário-de-contribuição", salário percebido ou declarado pelo trabalhador sobre o qual será incidida a alíquota previdenciária. (COSTA; ALMEIDA, 2018, p. 9).

\footnotetext{
${ }^{1}$ Jornal O Alto Acre (19 de dezembro de 2018).

2 Jornal O Alto Acre (19 de dezembro de 2018).

${ }^{3}$ Jornal O Alto Acre (19 de dezembro de 2018).
} 
Nessa perspectiva, as referidas autoras explicam que "o trabalhador autônomo somente poderá contribuir com uma alíquota menor que $20 \%$ sobre o salário declarado, se desistir de gozar uma aposentadoria por tempo de contribuição, aceitando tacitamente o benefício da aposentadoria por idade", fato que o pode deixar mais tempo sem pagamento de contribuição previdenciária, pois um dos critérios para ter acesso à aposentadoria por idade é: para a mulher 60 anos e para o homem 65 anos de idade, atualmente. (COSTA; ALMEIDA, 2018, p. 9). Já consideramos que nas estatísticas do IBGE, para o estado do Acre, em 2018, os trabalhadores formais, representavam 39,4 pessoas, apesar do instituto não informar o número de trabalhadores autônomos para aquele ano, é possível inferir que os outros 60,6\% estavam na informalidade, incluindo os trabalhadores autônomos.

Ao lembrar que a outra grande promessa da Reforma Trabalhista era reduzir a informalidade, ou seja, os empregos sem carteira assinada, Ronald Silka, professor de Direito e coordenador da área Jurídica do Centro Universitário Internacional Uninter afirmou em entrevista ao jornal $O$ Alto Acre, ${ }^{1}$ que esses números são indicadores de que a falta de vagas faz com que as pessoas, "por necessidade, encontrem outra fonte de renda. Esta, sem dúvida, é realizada por meio de serviços informais, ou também os conhecidos 'bicos'². Diante desses resultados após a aprovação da Reforma Trabalhista, os especialistas, a exemplo de Lúcio (2015), ressaltam que só com o crescimento econômico é possível gerar emprego. Considerando a realidade da economia acreana e sua dependência do setor terciário, de serviços e do funcionalismo público, seu crescimento econômico fica totalmente dependente do crescimento dos estados produtores do setor primário, para incrementar a movimentação de mercadorias no estado acreano.

Ainda outras questões não menos relevantes lembradas por Roubicek (2019), estão relacionadas ao esvaziamento dos direitos dos trabalhadores diante da depreciação do Ministério do Trabalho como órgão de amparo aos diretos trabalhistas. Pelas assertivas de Teixeira et al (2017, p. 61) houve uma "limitação do acesso à Justiça do Trabalho e limitação do poder da Justiça do Trabalho [pela] ampliação do papel dos mecanismos privados de conciliação, eficácia liberatória dos acordos, quebra do princípio da gratuidade". Diante da possibilidade do trabalhador de arcar com o ônus das ações trabalhistas, houve acentuado declínio das ações no Ministério do Trabalho, em comparação entre os momentos antes e depois da reforma entrar em vigência mostra que a queda foi mais acentuada em alguns lugares do

\footnotetext{
${ }^{1}$ Jornal O Alto Acre (19 de dezembro de 2018).

${ }^{2}$ Jornal O Alto Acre (19 de dezembro de 2018).
} 
Brasil do em que outros. Mas, conforme afirma Roubicek (2019), por todo o país houve queda de pelo menos $20 \%$ no número de processos novos, quando se compara os primeiros nove meses de 2017 e de 2019.

Ao comentar os impactos na queda das ações trabalhistas, Ferreira (2019) constatou em sua entrevista ${ }^{1}$ que as novas regras trabalhistas representaram uma diminuição de mais de 1,3 milhão de processos na Justiça do país. Nas concepções de Ferreira (2019, p. 2), apesar de ser impactante, "a menor redução entre os Estados foi registrada no Acre: foram menos de 9 mil processos antes da Reforma Trabalhista e em torno de 6,7 mil depois dela - queda de 24,7\%, segundo levantamento do jornal Correio do Povo, de Porto Alegre". Ao tratar das alterações sobre as ações trabalhistas na reforma, Roubicek (2019) compreende que houve uma questão interpretativa relacionada à questão da gratuidade nas ações trabalhistas.

Na concepção deste economista e jornalista, não houve desestimulo dos empregados em mover ações trabalhistas, mas a mudança "gerou um cuidado maior na propositura de ações. Então talvez aquelas que seriam as ações mais aventurosas tenham saído. Mas aquilo que era sério continuou, e até com mais qualidade". (Roubicek, 2019, p. 3). A desinformação e o medo também são fatores que não devem ser descartados na queda das ações trabalhista. Para Roubicek (2019), a lei criou a possibilidade "de determinar que o autor pague custas e honorários mesmo quando ele for beneficiário da justiça gratuita, autorizando-se inclusive descontar esses valores de outras verbas que venha a receber no processo, como, por exemplo, verbas rescisórias". (ROUBICEK, 2019, p. 3).

Para concluir essas discussões, registramos mais dois fatores de impactos da Reforma Trabalhista sobre o estado do Acre: a ampliação no número de desempregados e o percentual de famílias acreanas endividadas. O Jornal acreano Contilnet ${ }^{2}$, registrou os dados divulgados naquele mesmo dia pelo Instituto Brasileiro de Geografia e Estatística - IBGE - ao mostrar que o desemprego cresceu em 14 estados brasileiros no primeiro trimestre daquele ano. O mesmo jornal destacou que no Acre, "a taxa de desempregados foi de 18,0\% colocando-o na terceira posição do ranking dos estados onde mais pessoas estão sem emprego e ultrapassando - e muito - a média nacional que é $12,7 \%$ "3. A mesma fonte afirma que são 13,4 milhões de desempregados no país, ante um universo de 12,1 milhões no último trimestre do ano de 2018. Essa discussão abre um leque de possibilidades reflexivas que vão desde os problemas

\footnotetext{
${ }^{1}$ Jornal Online, AC 24 horas.

${ }^{2}$ Jornal acreano Contilnet, de 16 de maio de 2019.

${ }^{3}$ Jornal acreano Contilnet, de 16 de maio de 2019.
} 
econômicos no interior das famílias brasileiras e acreanas até o aumento nos problemas de saúde, com depressões, suicídios e o grave endividamento da sociedade por causa das novas mudanças nas legislações trabalhistas e previdenciária.

Para elencarmos apenas o endividamento das famílias, o Jornal Folha do Acre, noticiou que no estado do Acre, de acordo com o Serviço de Proteção ao Crédito - SPC Brasil, o número de inadimplentes cresceu 3,31\% em junho de 2019 comparado a junho de 2018. O jornal destacou ainda que esse dado estatístico, "ficou acima da média da região Norte $(2,16 \%)$ e acima da média nacional $(1,66 \%)$ "1. Em relação às instituições em que as pessoas se encontram mais endividadas, o referido jornal registrou que "o setor com participação mais expressiva do número de dívidas em junho no estado do Acre foi o bancário, com 32,31\% do total de dívidas" ${ }^{\text {" }}$ O quantitativo de dívidas em relação a cada cidadão acreano no mês de junho de 2019 ficou "em média 1,802 (uma vírgula oito dívida por pessoa) em atraso. O número ficou abaixo da média da região Norte (1,846 dívidas por pessoa inadimplente) e abaixo da média nacional registrada no mês (1,880 dívidas para cada pessoa inadimplente)"3.

$\mathrm{Na}$ entrevista concedida a Coll (2019), o sociólogo Ricardo Antes afirma que: "A contrarreforma trabalhista, aprovada durante o governo Temer, foi a legitimação jurídica da burla". (Grifo do autor). Nas análises desse pesquisador, o que aconteceu na prática foi agregar tudo que já acontecia no campo da ilegalidade, e da informalidade, acrescentando-se a isso, o trabalho intermitente, criando um aparato jurídico que se ajustou a uma cruel realidade préexistente à reforma. Para Antunes é como se você dissesse o seguinte: "o mercado é informal, então vamos criar um monstrengo jurídico para dar juridicidade e legalidade à informalidade" (COLL, 2019, p. 4). Para o sociólogo, o trabalho intermitente e a informalidade são a antessala de uma sociedade sem previdência social para o futuro.

Em relação ao discurso sob o pretexto da necessidade de uma Reforma Trabalhista moderno, Ricardo Antunes, concedeu uma entrevista para Coll (2019), onde analisa que o então presidente Temer não pode estar vinculado a nada que fale em moderno. O sociólogo afirma que "Temer é a expressão do velho, da forma mais grotesca do velho, é a expressão do pântano que domina a economia brasileira" pois em sua concepção há "uma exploração brutal do trabalho e uma espoliação brutal do conjunto da classe trabalhadora". (COLL, 2019, p. 5). Essa análise não pode ser entendida fora do contexto político em que a popularidade do governo

\footnotetext{
${ }^{1}$ Jornal Folha do Acre, 18 de julho de 2019.

${ }^{2}$ Jornal Folha do Acre, 18 de julho de 2019.

${ }^{3}$ Jornal Folha do Acre, 18 de julho de 2019.
} 
Temer encontrava entre 5\%, mas, ainda assim, não houve manifestações sociais suficientes para sequer preocupar, nem ele próprio, nem os partidários políticos, no Congresso Nacional, que votaram a favor da reforma. O governo Temer foi impulsionado pelo calor dos movimentos sociais que resultaram no impeachment de Dilma Rousseff, resultando numa espécie de anestésico social que impediu a sociedade se voltar contra uma reforma perversa, mas que se originava de um governo mediador dos anseios de mudanças requeridas pela população.

Em outra entrevista concedida a Sanz; Nader, (2016), sobre as possibilidades de mudanças, apesar de suas palavras terem sido registradas antes da Reforma Trabalhista do governo Temer, o sociólogo Ricardo Antunes lembrou que não devemos resumir "tudo ao pessimismo e mesmo à melancolia, temos um mosaico de lutas e movimentos sociais, experiências novas". (SANZ; NADER, 2016 p. 5). Para Antunes, os movimentos dos "secundaristas, do sindicalismo de classe, como Conlutas e Intersindical, de lutas pela base, dos movimentos sociais de terra, de moradia etc.”, são ainda instituições e ações que podem vislumbrar alguma esperança para o futuro. (SANZ; NADER, 2016 p. 5). Suas propostas encerram-se na seguinte questão: "Como avançar numa nova política radical, como soldar novos laços de solidariedade e de pertencimento de classe, ao invés de ficarmos na política de fracionamento e fragmentação?" (SANZ; NADER, 2016 p. 6). Para Antunes, esse é um dos desafios que se coloca para enfrentarmos.

\section{CONSIDERAÇÕES FINAIS}

O resultado desta pesquisa emergiu das discussões e debates realizados na disciplina Geografia do Trabalho e Conflitos Territoriais na Amazônia sob a responsabilidade do professor Dr. José Alves, no curso de Mestrado em Geografia do Programa de Pós-Graduação em Geografia - PPGEO, da Universidade Federal do Acre - UFAC, no segundo semestre de 2019. O objetivo foi analisar os efeitos da Reforma Trabalhista implementada no governo Temer no ano 2017, sobre o estado do Acre. Partimos de uma reflexão teórica e crítica de pesquisadores com larga experiência em pesquisas sobre a geografia do trabalho, a exemplo de Ricardo Antunes e Antonio Thomaz Junior, para compreender como a implantação daquelas mudanças afeta diretamente a classe trabalhadora de forma nefasta.

As considerações analíticas foram realizadas com a delimitação para buscar compreender os efeitos da Reforma Trabalhista efetivada no governo Temer sobre o estado do Acre em relação ao desemprego, em relação ao número de desocupados, as mudanças nos índices de trabalhos autônomos, além de buscar compreender como se deu o endividamento da 
sociedade acreana. Pela proposta inicial, acreditamos que os objetivos foram alcançados, apesar de não esgotar a discussão, tendo em vista que outros suportes midiáticos ficaram fora das discussões, o que poderia gerar ampliação do campo analisado e comparações dos posicionamentos, considerando os interesses de cada pessoa, grupo social ou instituição.

Pela temática extremamente relevante e considerando sua absoluta atualidade, a reflexão pode contribuir nos apontamentos e nas discussões de futuras pesquisas, principalmente sobre os efeitos da Reforma Trabalhista sobre a sociedade acreana. Vale destacar que o estado do Acre foi o segundo que mais apoiou o atual governo de Jair Bolsonaro pela votação nas urnas, fato que pode explicar tanto a apatia, apresentada no período da aprovação da Reforma Trabalhista no governo Temer, quanto ao mesmo comportamento diante da Reforma da Previdência assinada no governo de Jair Bolsonaro ${ }^{1}$. Nesse contexto, formou-se um quadro indicativo de que as reformas trabalhistas, previdenciárias, e a atual reforma econômica e administrativa, em curso, fazem parte de um único projeto de ultra direita, para implodir os direitos trabalhistas iniciados na era Vargas, e que estavam em vigor até a implementação das duas reformas em tela.

Passados quatro anos do impeachment de Dilma Rousseff, ocorrido em 31 de agosto de 2016, é possível afirmar que os discursos de necessidade de uma legislação trabalhista moderna, e a falácia de quebra da previdência, caso não acontecesse às reformas, foram engodos associados aos desgastes dos governos de esquerda, que facilitaram as aprovações de reformas adversas à população trabalhadora. O governo de Jair Bolsonaro foi empossado nesse contexto, com o apoio social fraudulentamente conquistado por fake News, populismos midiáticos, e uma enorme divisão social, econômica e política, entre defensores neoliberalistas, grandes empresários, capitalistas defensores do Estado mínimo, a classe trabalhadora e outros milhões de desempregados, ou em subempregos, sem-terra, sem teto, entre outras condições degradantes.

Quanto às perspectivas de ampliação desse campo temático pode ser inserida no contexto de novos estudos sobre os efeitos da Reforma Trabalhista aprovada no governo Temer, e efetivada no atual governo Bolsonaro associada aos acontecimentos desagradáveis que ambas as reformas estão impondo principalmente sobre a classe trabalhadora brasileira e acreana. Diante do exposto, a presente reflexão encontra-se aberta às futuras mudanças e às novas condições que inevitavelmente surgirão em consequência das investidas contra os direitos

\footnotetext{
${ }^{1}$ Temer e Bolsonaro defendem um mesmo projeto político neoliberal, com Reformas Trabalhistas, previdenciárias, política de teto de gastos, reforma administrativa, privatizações etc.
} 
trabalhistas tanto no governo de Michel Temer, quanto no atual governo de Jair Messias Bolsonaro.

\section{REFERÊNCIAS}

ACRE (Estado) Associação Comercial do Acre. ACISA apoia posicionamento de parlamentares que votaram a favor da Reforma Trabalhista. Jornal Contilnet online. Rio Branco: 2017. Disponível em: https://www.acisaac.org.br/314-2/. Acesso em: 09 fev. 2020.

ACRE (Estado) Associação Comercial do Acre. ACISA apoia posicionamento de parlamentares que votaram a favor da Reforma Trabalhista. Jornal Contilnet online. O Acre em um só lugar. Rio Branco: 5 de Maio de 2017. Disponível em: https://contilnetnoticias.com.br/2017/05/acisa-apoia-posicionamento-de-parlamentares-quevotaram-a-favor-da-reforma-trabalhista/. Acesso em: 09 fev. 2020.

CONTILNET. Acre é o terceiro estado com maior número de desempregados no Brasil, aponta IBGE. Jornal Contilnet, via Acre.com.br. 16 de Maio de 2019. Disponível em: https://www.acre.com.br/acre-e-o-terceiro-estado-com-maior-numero-de-desempregados-nobrasil-aponta-ibge/. Acesso em: 09 fev. 2020.

ALVES, José. As Revoltas dos Trabalhadores em Jirau (RO): degradação do trabalho represada na produção de energia elétrica na Amazônia. Orientador: Antonio Thomaz Júnior. 2014. Presidente Prudente: [s.n.], Tese (Doutorado em Geografia), 2014. 671 f. Disponível em: http://hdl.handle.net/11449/116027. Acesso em: 18 set. 2020.

ANTUNES, Ricardo. Os sentidos do trabalho: ensaios sobre a afirmação e a negação do trabalho. 6 ed. Boitempo, 2002.

BRASIL. Instituto Brasileiro de Geografia e Estatística. Cidades e Estados, Acre. Disponível em: https://www.ibge.gov.br/cidades-e-estados/ac/. Acesso em: 09 fev. 2020.

BRASIL, Janine; MELO, Quésia. Em Rio Branco, centrais sindicais protestam contra a Reforma Trabalhista. G1, Acre. Rio Branco: 10 nov. 2017. Disponível em: https:/g1.globo.com/ac/acre/noticia/em-rio-branco-centrais-sindicais-protestam-contra-areforma-trabalhista.ghtml. Acesso em: 19 set. 2019.

BRASIL. Lei $\mathbf{n}^{\mathbf{0}}$ 13.467, de 13 de julho de 2017. Altera a Consolidação das Leis do Trabalho (CLT), aprovada pelo Decreto-Lei $n^{0} 5.452$, de $1^{\circ}$ de maio de 1943, e as Leis $n^{\circ} 6.019$, de 3 de janeiro de 1974, 8.036, de 11 de maio de 1990, e 8.212, de 24 de julho de 1991, a fim de adequar a legislação às novas relações de trabalho. Disponível em: http://www.planalto.gov.br/ccivil 03/ ato2015-2018/2017/lei/113467.htm. Acesso em: 18 set. 2020.

CHAHAD, José Paulo Zeetano. Reforma Trabalhista de 2017: Principais Alterações no Contrato de Trabalho. Temas de economia aplicada, informações Fipe, 2017. Disponível em: http://downloads.fipe.org.br/content/downloads/publicacoes/bif/bif445-8-13.pdf. Acesso em: 24 fev. 2020. 
COLL, Liana. Aumento da miséria extrema, informalidade e desigualdade marcam os dois anos da Reforma Trabalhista. Jornal da Unicamp, Instituto humanista Unisinos, 11 novembro de 2019. Disponível em: http://www.ihu.unisinos.br/594278-aumento-da-miseria-extremainformalidade-e-desigualdade-marcam-os-dois-anos-da-reforma-trabalhista. Acesso em: 24 fev. 2020.

COSTA, Ana Cristina Pereira da; ALMEIDA, Maria Goretti de. A Reforma Trabalhista e seus desdobramentos para a classe trabalhadora. VI Seminário Cetros Crise e Mundo do Trabalho no Brasil desafios para a classe trabalhadora. UECE: Agosto de 2018. Disponível em: www.uece.br/eventos/seminariocetros/anais/trabalhos. Acesso em: 09 fev. 2020.

JORNAL Folha do Acre, via Acre.com.br 18 de julho de 2019. Da Amazônia para o Mundo. Percentual de famílias endividadas no Acre aumenta pelo sexto mês consecutivo, diz Acisa. Disponível em: https://www.acre.com.br/percentual-de-familias-endividadas-no-acreaumenta-pelo-sexto-mes-consecutivo-diz-acisa/. Acesso em: 09 fev. 2020.

FERREIRA Edmilson. Reforma da CLT reduz número de processos trabalhistas no Acre. Jornal on line, AC, 24 horas, dia 18 maio de 2019. Disponível em: https://ac24horas.com/2019/05/18/reforma-da-clt-reduz-em-247-numero-de-processostrabalhistas-no-acre/. Acesso em: 08 fev. 2020.

JORNAL O ALTO ACRE. Governo prometeu 2 milhões de vagas; criou 298,3 mil até agora, 19 de dezembro de 2018. Jornal O Alto Acre. com. Disponível em: https://oaltoacre.com/contratacoes-informais-aumentam-no-pais-apos-um-ano-de-reformatrabalhista/. Acesso em: 09 fev. 2020.

GUERRA, Alexandre et al. Variação da desocupação no Brasil (2016-2017): apontamentos sobre a desigualdade regional e de gênero. In: TEIXEIRA, Marilane Oliveira et al Contribuição crítica à Reforma Trabalhista. Campinas, SP: UNICAMP/IE/CESIT, 2017. 328 p. Disponível em: https://www.eco.unicamp.br/images/arquivos/Reformatrabalhista.pdf. Acesso em: 13 fev. 2020.

HERMANSON, Marcos. "Trabalho precário, intermitente, é a antessala do desemprego", diz Ricardo Antunes. Brasil de Fato, Futuro do trabalho. São Paulo (SP): 29 de Abril de 2019. Disponível em: https://www.brasildefato.com.br/2019/04/29/trabalho-precario-intermitente-ea-antessala-do-desemprego-diz-ricardo-antunes. Acesso em: 13 fev. 2020.

KREIN, José Dari; GIMENEZ, Denis Maracci; SANTOS, Anselmo Luís dos. (Orgs). Dimensões críticas da Reforma Trabalhista no Brasil. Campinas, SP: Curt Nimuendajú, 2018. 304 p. Disponível em: https://www.eco.unicamp.br/images/arquivos/LIVRODimensoesCriticas-da-Reforma-Trabalhista-no-Brasil.pdf. Acesso em: 13 fev. 2020.

LAPUENTE, Rafael Saraiva. O jornal impresso como fonte de pesquisa: delineamentos metodológicos Alcar, 2015. UFRGS, Porto Alegre, RS: 2015.

LÚCIO, Clemente Ganz. Desafios para o crescimento e o emprego. Estud. av. vol. 29 n. 85 São Paulo Sept./Dec. 2015. Disponível em: http://dx.doi.org/10.1590/S0103-40142015008500003. Acesso em: 09 fev. 2020. 
MÉSZÁROS, István. O marxismo hoje. Crítica Marxista, São Paulo, Brasiliense, v. 1, n. 2, 1995, p. 129-137. Entrevista concedida a Chris Arthur e Joseph McCarney. Disponível em: https://www.ifch.unicamp.br/criticamarxista/arquivos biblioteca/entrevista20Entrevista.pdf.

Acesso em: 09 fev. 2020.

PRIEB, Sérgio A.M.; CARCANHOLO, Reinaldo A. O trabalho em Marx. In: CARCANHOLO, Reinaldo A. (Org.). Capital: essência e aparência. Vol. 1. São Paulo: Expressão Popular, 2011.p. 147-161.

ROCHA, Rafael. Reforma trabalhista! um guia completo das mudanças nos direitos trabalhistas. Publicado em julho de 2017. Disponível em: https://jus.com.br/artigos/59115/reforma-trabalhista. Acesso em: 09 fev. 2020.

ROUBICEK, Marcelo. Como ficou o quadro de ações trabalhistas 2 anos após a reforma. Expresso, 032019.2 nov. Disponível em: https://www.nexojornal.com.br/expresso/2019/11/03/Como-ficou-o-quadro-dea $\%$ C3\%A7\%C3\%B5es-trabalhistas-2-anos-ap \%C3\%B3s-a-reforma. Acesso em: 09 fev. 2020.

SANZ, Raphael e NADER, Valéria. A degradação institucional brasileira chegou ao seu ponto mais agudo. Entrevista com Ricardo Antunes Correio da Cidadania 2 de abril de 2016. Disponível em: https://racismoambiental.net.br/2016/04/02/ricardo-antunes-a-degradacaoinstitucional-brasileira-chegou-ao-seu-ponto-mais-agudo/. Acesso em: 09 fev. 2020.

SILVA, André Ricardo Lopes da; LEITE, Milca Micheli Cerqueira. Estratégias do capitalismo e Reforma Trabalhista: a instrumentalização do sujeito trabalhador. In: RAMOS, Gustavo Teixeira, et al (coords.) O golpe de 2016 e a Reforma Trabalhista: narrativas de resistência. Bauru: Canal 6, 2017. 391 p.

TEIXEIRA, Marilane Oliveira et al Contribuição crítica à Reforma Trabalhista. Campinas, SP: UNICAMP/IE/CESIT, 2017. 328 p

THOMAZ JUNIOR, Antônio. Geografia do Trabalho por Inteiro. Revista Pegada, Presidente Prudente. v. 19, n. 02, p. 06-56, maio-agosto, 2018. Disponível em: https://revista.fct.unesp.br/index.php/pegada/article/view/6000. Acesso em: 12 fev. 2020. 